climate, clothing, lifestyle, sex, age and side. Journal of Anatomy, 223(2), p. 133-151.

6. Buller.L.T., Rosneck.J., Monaco.F.M., và cộng sự. (2012). Relationship between proximal femoral and acetabular alignment in normal hip joints using 3-dimensional computed tomography. American Journal of Sports Medicine, 40(2), p.
367-375.

7. Reikeråls.0., Bjerkreim.I., và Kolbenstvedt.A. (1983). Anteversion of the Acetabulum and Femoral Neck in Normals and in Patients with Osteoarthritis of the Hip. Acta Orthopaedica Scandinavica, 54(1), p. 18-23.

\title{
KIẾN THỨC CỦA SINH VIÊN ĐIỀU DƯỡNG NĂM CUỐI TRƯỜNG ĐẠI HỌC ĐIỀU DƯỠNG NAM ĐINH VỀ DƯ PHÒNG PHƠI NHIỄM VỚI MÁU, DICH CO' THỂ
}

\author{
Vũ Thị Là ${ }^{1}$, Hoàng Thị Minh Thái ${ }^{1}$, \\ Nguyễn Mạnh Dũng1, Phạm Văn Tùng ${ }^{1}$, Nguyễn Thị Lĩnh ${ }^{1}$
}

TÓM TẮT

Mục tiêu: mô tả kiến thức của sinh viên điều dưỡng năm cuối Trường Đại học Điều dưỡng Nam Định về phòng ngừa phơi nhiễm với máu, dịch cơ thể. Đối tượng và phương pháp: Sinh viên đại hợc điều dưỡng chính quy năm cuối được lựa chon ngẫu nhiên và trả lời câu hỏi bằng phiếu khảo sát. Kết quả: Điểm trung bình khái niệm và phương thức; chăm sóc sức khỏe cơ bản; biện pháp phòng ngừa; sơ cứu tại chỗ; báo cáo và lập biên bản; đánh giá nguy cơ và nguồn lây; điều trị dự phòng sau phơi nhiễm lần lượt là 8,38; 8,$36 ; 9,38 ; 7,84 ; 8,13 ; 7,07$ và 5,99điểm. Kết luận: Kiến thức phòng ngừa phơi nhiếm với máu, dịch tiết của sinh viên điều dưỡng Nam Đinh đang ở mức độ trung bình với điểm trung bình chung là 7,71 \pm 0,71điểm. Các lĩnh vực sinh viên đang có kiến thức ở mức trung bình là sơ cứu tại chỗ và đánh giá nguồn lây nhiếm

Tư khóa: Kiến thức, sinh viên điều dưỡng, phơi

\section{SUMMARY}

FINAL-YEAR NURSING STUDENTS' KNOWLEDGE OF PREVENTING EXPOSURE

TO BLOOD AND BODY FLUIDS IN NAM DINH UNIVERSITY OF NURSING

Objective: Describe final-year nursing students' knowledge of preventing exposures to blood and body fluidsin Nam Dinh University of Nursing. Subjects and method: Finalyear full-time nursing students were randomly selected to answerquestionnaires. Results: mean scoresof concept and mode; fundamental health care; prevention measures; emergency first-aid; reporting and making a report; assessment of risk and the source of infection are in turn 8.38; 8.36; 9.38; 7.84; 8.13; 7.07 and 5.99points. Conclusion: Final-year nursing students'

${ }^{1}$ Trường ĐH Điều dưỡng Nam Định Chịu trách nhiệm chính: Vũ Thị Là Email: vula_ynd@yahoo.com.vn Ngày nhận bài: 21/3/2021

Ngày phản biên khoa học: 25/4/2021 Ngày duyệt bài: 6/5/2021 knowledge of preventing exposure to blood and body fluidin Nam Dinh University of Nursing is moderate with the mean score is $7.71 \pm 0.71$ points $/ 10$ points. The domainsin which students' knowledge is at an average level are emergency first-aid and assessmentof infection source.

Keyword: Knowledge, nursing student, Occupational exposure.

\section{I. ĐĂT VẤN ĐỀ}

Thực hành lâm sàng là một khía cạnh chuyên sâu của chương trình đào tạo và là một thành phân cốt Iõi trong giáo dục và đào tạo điêu dưỡng hiện nay. Đào tạo thực hành lâm sàng diễn ra trong các môi trường lâm sàng khác nhau, với mục đích rèn luyện kỹ năng tư duy và kỹ năng ra quyết định lâm sàng cũng như phát triển năng lực thực hành nghề nghiêp điều dưỡng. Tuy nhiên, môi trường lâm sàng tại bệnh viện luôn tiềm ẩn các yếu tố rủi ro nghề nghiệp như môi trường độc hại, các loại thuốc hóa trị, bạo lực, tổn thương do kim tiêm/vật sắc nhọn, các vấn đề về da, dị ứng latex, các bênh truyên nhiễm lây lan qua đường máu/dịch tiết, các vấn đề về sức khỏe tâm thần. Đặc biệt, phơi nhiễm với các bệnh truyền nhiễm qua đường máu hoặc dịch cơ thể đang là một vấn đề cân được quan tấm ở sinh viên điều dưỡng.

Phơi nhiễm với máu, dich cơ thể ở sinh viên điêu dưỡng là tai nạn rủi ro trong quá trình thực hành nghề[8]. Các phơi nhiễm có thể xảy ra đối với sinh viên điều dưỡng chủ yếu là tổn thương qua da từ kim tiêm hoăc vât sắc nhọn có dính máu, dịch tiết của người nhiễm hoặc máu, dịch cơ thể của người bị nhiễm tiếp xúc với da tổn thương hoặc bắn vào niêm mạc[3],[5]. Hậu quả của việc bị phơi nhiễm với máu, dịch cơ thể làm tăng nguy cơ lo âu, căng thẳng của sinh viên, nghiêm trọng hơn là nguy cơ nhiếm các tác nhân gây bệnh qua đường máu như: HBV, HCV, 
HIV ,... và đe dọa đến tính mạng [4].

Sinh viên điều dưỡng năm cuối, với tư cách là các điều dưỡng viên trong tương lai, sẽ cải thiện chất lượng và sự an toàn của việc chăm sóc người bệnh, đi đầu trong việc phòng ngừa và kiểm soát nhiễm khuẩn bênh viện nói chung và dự phòng phơi nhiễm nghề nghiệp nói riêng. Do vậy đề tài này được thực hiện để đánh giá kiến thức của sinh viên điều dưỡng năm cuối trong phòng ngừa phơi nhiễm với máu, dịch cơ thể để có cơ sở điều chỉnh các hoat động đào tạo của Nhà trường với hy vong cải thiện được kiến thức, từ đó có thể cải thiện được hành vi tích cực của sinh viên.

\section{II. ĐỐl TƯƠNGG VÀ PHƯƠNG PHÁP NGHIÊN CỨU}

2.1. Thiết kế nghiên cứu: Mô tả cắt ngang.

2.2. Đối tượng nghiên cứu: Sinh viên Đại học điều dưỡng năm cuối Trường Đại học điều dưỡng Nam Định trong thời gian nghiên cứu đạt các tiêu chuẩn chọn mầu.

- Tiêu chuẩn lựa chọn: Sinh viên điều dưỡng năm cuối của Trường Đại học Điều dưỡng nam Định và đã học học phần kiểm soát nhiễm khuẩn trong chương trình đào tạo và đạt điểm $\mathrm{D}$ trở lên.

- Tiêu chuẩn loại trừ: Sinh viên vắng mặt tại thời điểm thu thập số liệu; Sinh viên từ chối tham gia nghiên cứu.

2.3. Thời gian và địa điểm

- Thời gian nghiên cứu: từ tháng 9/2019 đến tháng 8/2020.

\section{- Địa điểm: Trường Đại học Điều dưỡng Nam Định}

\subsection{Mẫu và phương pháp chọn mẫu}

- Cõ̃ mẫu: Được tính bằng công thức ước tính cho một tỷ lệ với $d=0,05 ; p=0,49 ;$ Tính được cõ mẫu cho nghiên cứu là 160 sinh viên.

- Phương pháp chọn mẫu: Trong tổng số sinh viên là 749 sinh viên điều dưỡng chính quy khóa 12 , chúng tôi tiến hành bốc thăm ngẫu nhiên 03 lớp học phần trong tổng số 12 lớp học phần Đường lối cách mạng đảng cộng sản Việt Nam. Kết quả lớp học phần 12.2; 12.5 và 12.7 đã được chọn với tổng số sinh viên là 194 sinh viên. Dựa trên tiêu chí lựa chọn và loại trừ chúng tôi chọn được 182 sinh viên tham gia vào nghiên cứu.

2.5. Công cụ và phương pháp đánh giá. Công cụ đánh giá kiến thức về dự phòng phơi nhiễm với máu, dị̣ch cơ thể của sinh viên dựa trên các hướng dẫn của Bộ Y tế [1], [2]. Bộ cấu hỏi gồm 2 phần: PhầnA: Thông tin chung về đối tượng nghiên cứu gồm 7 câu hỏi; Phần B. Kiến thức của sinh viên về phơi nhiếm với máu và dịch cơ thể gồm gồm 73 câu hỏi, được thiết kế có 2 phương án trả lời là đúng hoăc sai. Mỗi câu trả lời đúng được 1 điểm, trả lời sai 0 điểm. Điểm trung bình kiến thức của từng lĩnh vực trên được quy về thang điểm điểm 10. Điểm trung bình chung kiến thức của sinh viên về phơi nhiễm và dự phòng phơi nhiễm là tổng trung bình chung của các lĩnh vực kiến thức trên theo thang điểm 10 và được phân loại theo mức độ kiến thức như sau:

\begin{tabular}{|c|c|}
\hline Mức điếm & Phân loại kiến thức \\
\hline $8-10$ điếm & Tốt \\
\hline $5,0-7,9$ điếm & Trung bình \\
\hline $0-4,9$ điếm & Kém \\
\hline
\end{tabular}

Thang đo kiến thức được thẩm định và hiệu chỉnh bới các chuyên gia trong lĩnh vực kiểm soát nhiễm khuẩn và có độ tin cậy cao với hệ số tương quan giữa hai lần kiểm tra trên cùng một đối tượng là 0.818

2.6. Phương pháp thu thập số liệu: Tự điền dựa trên bộ câu hỏi soạn sẵn.

2.7. Xử lý và phân tích số liệu: Phân tích mô tả được thực hiện trên phần mềm SPSS 16.0.

\section{KẾT QUẢ NGHIÊN CỨU}

3.1. Đặc điểm của đối tượng nghiên cứu Bảng 3.1. Phân bố giới tính và tình trạng tiêm vắc xin viêm gan $B(n=182)$

\begin{tabular}{|c|c|c|c|}
\hline \multicolumn{2}{|c|}{ Nội dung } & $\begin{array}{c}\text { Số } \\
\text { lượng }\end{array}$ & $\begin{array}{c}\text { Tỷ lệ } \\
\text { \%o }\end{array}$ \\
\hline \multirow{2}{*}{ Giới tính } & Nam & 19 & 10,4 \\
\cline { 2 - 4 } & Nữ & 163 & 89,6 \\
\hline \multirow{2}{*}{$\begin{array}{c}\text { Đã tiêm vắc } \\
\text { xin VGB }\end{array}$} & Đã tiêm & 159 & 87,4 \\
\cline { 2 - 4 } & Chưa tiêm & 23 & 12,6 \\
\hline
\end{tabular}

Nhân xét: Khảo sát 182 sinh viên điều dưỡng khóa 12 trong đó nữ sinh chiếm $89 \%$ và $87,4 \%$ sinh viên đã tiêm phòng vắc xin Viêm gan $B$.

3.2. Kiến thức về khái niệm, phương thức phơi nhiếm qua đường máu, dịch tiết

Bảng 3.2. Kiến thức về khái niệm, phương thức phơi nhiếm

\begin{tabular}{|c|c|c|}
\hline $\begin{array}{c}\text { Kiến thức về khái niệm } \\
\text { và phương thức PN }\end{array}$ & $\begin{array}{c}\text { Số lượng } \\
(\mathbf{n})\end{array}$ & $\begin{array}{c}\text { Tỷ lệ } \\
(\mathbf{\%})\end{array}$ \\
\hline Tốt & 136 & 74,7 \\
\hline Trung bình & 42 & $\mathbf{2 3 , 1}$ \\
\hline Kém & 4 & $\mathbf{2 , 2}$ \\
\hline Tống số & $\mathbf{1 8 2}$ & $\mathbf{1 0 0}$ \\
\hline $\begin{array}{c}\text { Điếm trung bình } \pm \text { độ } \\
\text { lệch chuẩn }\end{array}$ & \multicolumn{2}{|c|}{$\mathbf{8 , 3 8} \pm \mathbf{1 , 7 7}$} \\
\hline
\end{tabular}

Nhân xét: Điếm trung bình chung kiến thức về khái niệm và phương thức là $8,38 \pm 1,77$ điểm. Tỷ lể sinh viên có kiến thức mức tốt đạt $74,7 \%$, mú́c trung bình là $23,1 \%$ bản
3.3. Kiến thức về chăm sóc sức khỏe cơ 


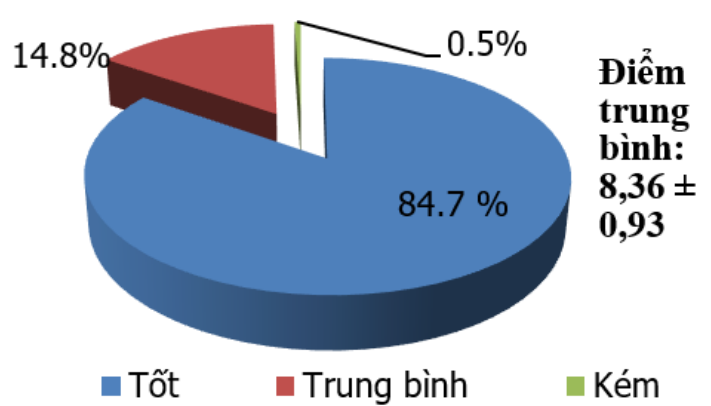

Biểu đồ 3.1. Kiến thức về chăm sóc sức khỏe cơ bản

Nhận xét: Điểm trung bình chung kiến thức về chăm sóc sức khỏe cơ bản đạt $8,36 \pm 0,93$ điểm. Trong đó tỳ lề sinh viên có kiến thức mức tốt đạt 84,5\%; múc trung bình chiếm 14,8\%.

3.4. Kiến thức về các biện pháp phòng ngừa phơi nhiễm với máu/dịch tiết

Bảng 3.3. Kiến thức về các biện pháp phòng ngừa phơi nhiếm với máu/dịch tiêt

\begin{tabular}{|c|c|c|}
\hline $\begin{array}{c}\text { Kiến thức về các biện } \\
\text { pháp phòng ngừa }\end{array}$ & $\begin{array}{c}\text { Số } \\
\text { lượng }\end{array}$ & Tỷ lệ \\
\hline Tốt & 174 & $\mathbf{9 5 , 6}$ \\
\hline Trung bình & 8 & 4,4 \\
\hline Kém & 0 & 0 \\
\hline Tống số & $\mathbf{1 8 2}$ & $\mathbf{1 0 0}$ \\
\hline $\begin{array}{c}\text { Điếm trung bình } \pm \text { độ } \\
\text { lệch chuẩn }\end{array}$ & $\mathbf{9 , 3 8} \pm \mathbf{0 , 8 3}$ \\
\hline
\end{tabular}

Nhận xét: Điểm trung bình chung kiến thức về biện pháp phòng ngừa đạt $9,38 \pm 0,83$ điểm, trong đó tỷ lê sinh viên có kiến thức tốt đạt $95,6 \%$, mức trung bình $4,4 \%$.

3.5. Kiến thức về sơ cứu tại chỗ sau khi bị phơi nhiễm

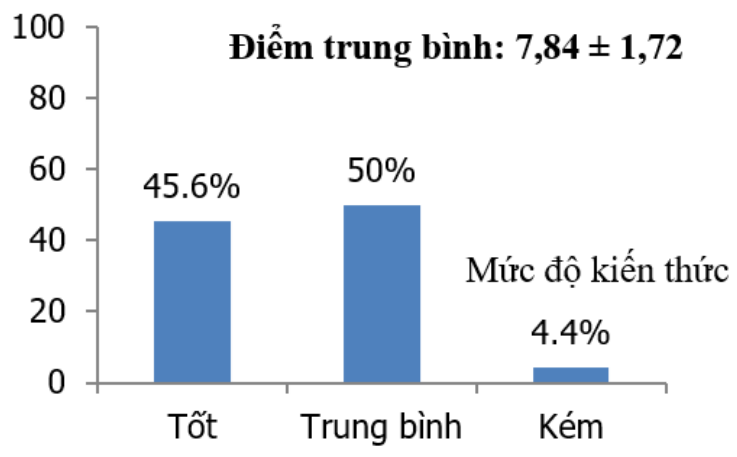

Biểu đồ 3.2. Kiến thức về sơ cứu tại chỗ sau khi bi phơi nhiễm

Nhận xét: Điểm trung bình chung kiến thức về sơ cứu tại chỗ sau khi bị phơi nhiễm là $7,84 \pm$ 1,72 điểm. Trong đó tỷ lệ sinh viên có kiến thức mức tốt chiếm $45,6 \%$, mức trung bình $50,0 \%$, mức kém 4,4\%.
3.6. Kiến thức về kỹ năng làm báo cáo và lập biên bản

Bảng 3.4. Kiến thức báo cáo, làm biên bản $(n=182)$

\begin{tabular}{|c|c|c|}
\hline $\begin{array}{c}\text { Kiến thức về làm báo } \\
\text { cáo và lập biên bản }\end{array}$ & $\begin{array}{c}\text { Số } \\
\text { lượng }\end{array}$ & Tỷ lệ \\
\hline Tốt & 129 & 70,9 \\
\hline Trung bình & 4 & $\mathbf{2 , 2}$ \\
\hline Kém & 49 & $\mathbf{2 6 , 9}$ \\
\hline Tổng số & $\mathbf{1 8 2}$ & $\mathbf{1 0 0}$ \\
\hline $\begin{array}{c}\text { Điếm trung bình } \pm \text { độ } \\
\text { lệch chuẩn }\end{array}$ & \multicolumn{2}{|c|}{$\mathbf{8 , 1 3} \pm \mathbf{2 , 9 6}$} \\
\hline
\end{tabular}

Nhận xét: Điếm trung bình chung kiến thức về làm báo cáo và lập biên bản là $8,13 \pm 2,96$ điểm. Trong đó tỷ lệ sinh viên có kiến thức tốt là $70,9 \%$; vẫn còn $26,9 \%$ sinh viên có kiến thức kém.

3.7. Kiến thức về đánh giá nguy cơ và đánh giá nguồn lây

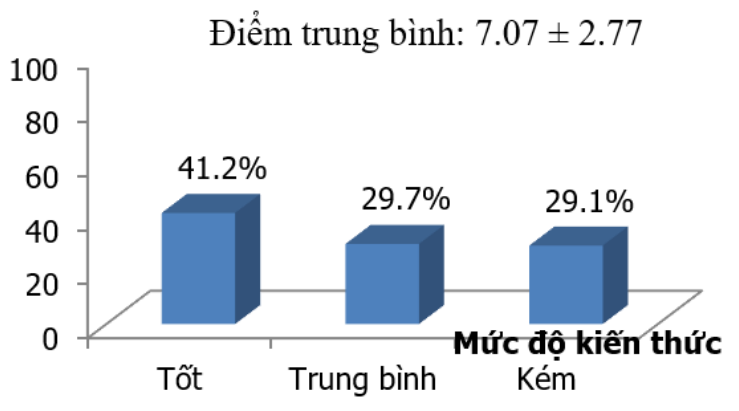

Biểu đồ 3.3. Kiến thức về đánh giá nguy cơ

Nhận xét: Điểm trung bình chung kiến thức về đánh giá nguy cơ đạt $9,14 \pm 1,48$ điểm. Trong đó tỷ lệ sinh viên có kiến thức mức trung bình chiếm $28,6 \%$.

3.8. Kiến thức về điêu trị dự phòng sau phơi nhiễm

Bảng 3.5. Kiến thức điều trị dự phòng sau phơi nhiếm $(n=182)$

\begin{tabular}{|c|c|c|}
\hline $\begin{array}{c}\text { Kiến thức về đánh giá } \\
\text { nguồn gây phơi nhiềm }\end{array}$ & $\begin{array}{c}\text { Số } \\
\text { lượng }\end{array}$ & Tỷ lệ \\
\hline Tốt & 42 & $23,1 \%$ \\
\hline Trung bình & 106 & $58,2 \%$ \\
\hline Kém & 34 & $18,7 \%$ \\
\hline Tống số & 182 & $\mathbf{1 0 0}$ \\
\hline $\begin{array}{c}\text { Điếm trung bình } \pm \text { độ } \\
\text { lệch chuẩn }\end{array}$ & \multicolumn{2}{|c|}{$\mathbf{5 , 9 9} \pm \mathbf{1 , 9 8}$} \\
\hline
\end{tabular}

Nhận xét: Điểm trung bình chung kiến thức về điều trị dự phòng sau phơi nhiễm là $5,99 \pm$ 1,98 điểm. Trong đó tỷ lệ sinh viên có kiến thức trung bình chiếm $58,2 \%$ và kiến thức kém chiếm $18,7 \%$.

3.9. Kiến thức chung về dự phòng phơi nhiễm với máu/dịch tiết 
Bảng 3.6. Kiến thức chung về dự phòng phơi nhiếm với máu/dịch tiêt

\begin{tabular}{|c|c|c|}
\hline $\begin{array}{c}\text { Kiến thức chung về dự } \\
\text { phòng phơi nhiếm }\end{array}$ & $\begin{array}{c}\text { Số } \\
\text { lượng }\end{array}$ & Tỷ lệ \\
\hline Tốt & 66 & 36,3 \\
\hline Trung bình & 116 & 63,7 \\
\hline Kém & 0 & 0 \\
\hline Tống số & $\mathbf{1 8 2}$ & $\mathbf{1 0 0}$ \\
\hline $\begin{array}{c}\text { Điếm trung bình } \pm \text { độ } \\
\text { lệch chuẩn }\end{array}$ & $\mathbf{7 , 7 1} \pm \mathbf{0 , 7 1}$ \\
\hline
\end{tabular}

Nhận xét: Điểm trung bình chung kiến thức về dự phòng phơi nhiễm là $7,71 \pm 0,71$ điểm, trong đó tỷ lệ sinh viên có kiến thức mức trung bình chiếm 63,7\%.

\section{BÀN LUÂN}

4.1. Kiến thức của $\sinh$ viên về khái niệm, phương thức phơi nhiếm. Kết quả tại bảng 3.2 cho thấy kiến thức của sinh viên về khái niệm và phương thức gây phơi nhiễm khá tốt điểm trung bình chung là $8,38 \pm 1,77$ điểm/10 điểm, trong đó kiến thức đạt mức tốt là $74,7 \%$. Kết quả cao như vậy là do đối tượng trong nghiên cứu của chúng tôi là sinh viên điều dưỡng năm cuối đã học học phần kiểm soát nhiễm khuẩn (02 tín chỉ) trong chương trình đào tạo. Tuy nhiên, vẫn còn $23,1 \%$ sinh viên có kiến thức ở mức trung bình và $2,2 \%$ sinh viên có kiến thức mức kém, sở dĩ còn một số sinh viên có kiến thức chưa đúng như vậy là do sau gần 2 năm học học phần kiểm soát nhiễm khuẩn một số bạn có thể đã quên đi một số kiến thức, do vậy việc nhắc lại kiến thức là rất quan trọng giúp sinh viên hoàn thiện nhận thức về phơi nhiễm với hy vọng có thể cải thiện hành vi trên lâm sàng.

4.2. Kiến thức về chăm sóc sức khỏe nghề nghiệp cớ bản. Kiến thức của sinh viên về chăm sóc sức khỏe nghề nghiệp cớ bản cũng khá tốt với điểm trung bình chung 8,36 điểm/10 điểm, trong đó tỷ lệ sinh viên có kiến thức mức tốt đạt $84,6 \%$, chỉ còn $14,8 \%$ ở mức trung bình và $0,5 \%$ ớ mức kém. Alhowaish, M.I. và cộng sự (2017) cũng cho kết quả tương tự khi ông cho rằng $86,5 \%$ sinh viên y khoa biết vắc xin có thể ngăn ngừa lây nhiễm HBV[5].

4.3. Kiến thức về các biên pháp phòng ngữa phơi nhiễm với máu/dịch cớ thể. Phương tiện phòng hộ cá nhân là một trong những biện pháp hữu hiệu để giúp nhân viên y tế nói chung và sinh viên điều dưỡng nói riêng tự tin hơn trong thực hành chăm sóc và phòng ngừa hiệu quả phơi nhiễm do máu, dịch gây ra. Kết quả nghiên cứu tại bảng 3.7 cho thấy sinh viên điều dưỡng trong nghiên cứu có kiến thức ở mức tốt về các biện pháp phòng ngừa phơi nhiễm với điểm trung bình chung đạt 9,38 điểm/10 điểm, trong đó tỷ lệ sinh viên có kiến thức mức tốt đat $95,6 \%$, chỉ còn $4,4 \%$ ở mức trung bình. Kết quả nghiên cứu của chúng tôi cũng tương tự nghiên cứu của Anjana, $A$. P. và cộng sự năm 2018 cho rằng họ có kiến thức tốt về phòng ngừa quản lý phơi nhiễm [6].

4.4. Kiến thức về sớ cứu tại chỗ sau khi bị phơi nhiễm. Kết quả nghiên cứu của chúng tổi tại biểu đồ 3.2 cho thây điểm trung bình kiến thức về sơ cứu tại chỗ chỉ ở mức trung bình (7,84 điểm/10 điểm), trong đó tỷ lệ sinh viên có kiến thức về vấn đề này ở mức trung bình chiếm $50 \%$ và mức kém là $4,4 \%$.Việc xử lý tai chỗ chưa đúng có thể làm tăng nguy cơ nhiễm từ phơi nhiễm [2]. Do vậy rất cần thiết phải củng cố lại kiến thức xử trí tại chô̂ cho sinh viên để sinh viên có thể tự tin xử trí ngay vị trí phớ nhiễm đúng nhất.

4.5. Kiến thức về kỹ năng báo cáo và làm biên bản. Kết quả nghiên cứu tại bảng 3.4 chỉ ra sinh viên điều dưỡng trong nhóm nghiên cứu có kiên thức ở mức tốt về làm báo cáo và lập biên bản với điểm trung bình chung đạt 8,13 điểm/10 điểm, trong đó tỷ lệ sinh viên có kiến thức về làm báo cáo và lập biên bản ở mức tốt chiếm $70,9 \%$. Việc báo cáo và làm báo cáo phơi nhiễm là thủ tục pháp lý để người bị phơi nhiễm được theo dõi, quản lý và được hưởng các quyền lợi về điều trị dự phòng phơi nhiếm và điêu trị bệnh nếu bị nhiếm bệnh từ phơi nhiễm.

4.6. Kiến thức về đánh giá nguy cơ và đánh giá nguồn lây. Đánh giá nguy cơ và đánh giá nguî̀n phơi nhiễm giúp cho người bị phơi nhiễm có hướng xử lý đúng và kịp thời và mang lại hiệu quả dự phòng nhiễm bệnh cao. Kết quả nghiên cứu tại biểu đồ 3.3 cho thấy sinh viên trong nhóm nghiên cứu có kiến thức ở mức trung bình về đánh giá nguồn gây phơi nhiễm với điểm trung bình chung là 7,07 điểm/10 điểm, trong đó tỷ lệ sinh viên đạt mức kém là $29,1 \%$, mức trung bình là $29,7 \%$, chỉ có $41,2 \%$ ở mức tốt. Tác giả Endalew, G.S. (2014) cũng cho kết quả tương tự tỷ lệ sinh viên điều dưỡng có kiến thức đúng về trường hợp phải điều trị dự phòng sau phơi nhiễm qua kim tiêm hoặc vết cắt 86 $(46.5 \%)$; qua niêm mạc mắt và miệng là 55(29.7\%); qua da bị tổn thương 24.2\% [7].

\subsection{Kiến thức về điêu trị dự phòng sau} phơi nhiễm. Điều trị dự phòng sau phơi nhiễm sẽ giúp giảm tỷ lệ nhiễm bệnh từ phơi nhiễm cao đặc biệt. Kết quả nghiên cứu chỉ ra kiến thức về điều trị dự phòng sau phơi nhiễm của sinh viên 
trong nhóm nghiên cứu ở mức trung bình với5,99 $\pm 1,98$ điểm, Trong đó tỷ lệ sinh viên có kiến thức trung bình chiếm $58,2 \%$ và kiến thức kém chiếm $18,7 \%$. Kết quả nghiên cứu của chúng tôi cũng phù hợp với nghiên cứu của Endalew, G.S. (2014) phần lớn (63\%) sinh viên có kiến thức không đây đủ về PEP của HIV, 91(49.2\%) sinh viên điêuu dưỡng báo cáo rằng đã từng nghe về PEP [7].

4.8. Kiến thức chung vê dự phòng phơi nhiễm. Nhìn chung kiến thức của sinh viên về dư phòng phơi nhiểm ở mức đô trung bình. Kết quả bảng 3.6 với điểm trung bình chung là 7,71 $\pm 0,71$ điểm, trong đó tỷ lệ sinh viên có kiến thức ở mức trung bình chiếm $63,7 \%$, chỉ có $36,3 \%$ là mức tốt.Kết quả nghiên cứu của chúng tôi tương tự môt số nghiên cứu cho thấy điểm kiến thức của sinh viên điều dưỡng về các biện pháp phòng ngừa tổn thương do vật sắc nhọn cũng ở mức trung bình[7],[8].

\section{KẾT LUÂ̂N}

Kiến thức chung của sinh viên điều dưỡng năm cuối về phòng ngừa phơi nhiễm với máu, dịch cơ thể ở mức trung bình với điểm trung bình chung đạt 7,71 $\pm 0,71$ (thang điểm 10). Trong có tỷ lệ sinh viên có kiến thức mức trung bình chiếm $63,7 \%$ và chỉ có $36,3 \%$ sinh viên có kiến thức tốt.

Các lĩnh vực sinh viên có kiến thức tốt là: Kiến thức về khái niệm, phương thức phơi nhiễm; chăm sóc sức khỏe nghề nghiệp cơ bản; các biện pháp phòng ngừa; báo cáo và lập biên bản với điểm số trung bình lần lượt là 8,38 điểm; 8,64 điểm; 8,36 điểm; 9,38 điểm và 9,14 theo thang điểm 10 .
Các lĩnh lực sinh viên có kiến thức chưa tốt (ở mức trung bình) là: Kiến thức về sơ cứu tại chồ; đánh giá nguồn gây phơi nhiễm với điểm số trung bình lần lượt là 7,84 điểm; 7,07 điểm;

\section{TÀI LIÊU THAM KHẢO}

1. Bộ $\mathbf{Y}$ tế (2012). Hướng dẫn tiêm an toàn trong các cơ sở khám, chữa bênh. Ban hành kèm theo Quyết định số 3671/QĐ-BYT của Bộ trưởng Bộ Y tế về việc phê duyệt các Hướng dẫn kiểm soát nhiếm khuân.

2. Bộ Y tế (2012).Tài liệu đào tạo phòng và kiểm soát nhiễm khuân, Nhà xuất bản y học, Hà Nội.

3. Lê Thị Anh Thư (2010). Hiệu quả của chương trình phòng ngừa phơi nhiễm do nghề nghiệp tại Bệnh viện Chợ Rẫy, Tap chí Y học Thành Phố Hồ Chí Minh, 14(2), tr. 429-435.

4. Ah Al-Hazmi (2015). Knowledge, attitudes, and practice of medical students regarding occupational risks of hepatitis B virus in college of medicine, aljouf university, Annals of medical and health sciences research, 5(1), pp. 13-19.

5. M.I. Alhowaish and et al. (2017). Knowledge, attitudes and practices toward prevention of hepatitis $B$ virus infection among medical students at Northern Border University, Arar, Kingdom of Saud Arabia.Electronic physician, 9(9), pp. 5388-5394.

6. A. P. Anjana, Gisha Joseph and Revathy Valsan (2018).Assessment of Knowledge Regarding Post exposure Prophylaxis Following Needle Stick Injury among b. Sc. Nursing Students.Indian Journal of Public Health Research \& Development, 9, p. 6.

7. G.S. Endalew (2014). Assessment of Level of Knowledge and Practice of Nursing and Midwifery Students on HIV Post Exposure Prophylaxis in Hawassa University, Ethiopia.Journal of HIV for Clinical and Scientific Research, 1(1), pp. 1-6.

8. Dixit Sanjay and et al. (2010). Impact of Educational Intervention Measures on Knowledge regarding HIV/ Occupational Exposure and Post Exposure Prophylaxis among Final Year Nursing Students of a Tertiary Care Hospital in Central India.Online Journal of Health \& Allied Sciences, 8.

\section{ẢNH HƯỞNG CỦA NHAI KEO CAO SU XYLITOL ĐẾN LƯU LƯỢNG VÀ pH NƯỚC BỌT}

\section{TÓM TẮT}

Nghiên cứu can thiệp không đối chứng được thức hiện trên 43 sinh viên trường Đại học Y Dược Thái Nguyên được thực hiện để đánh giá ảnh hưởng của nhai kẹo cao su xylitol đến lưu lượng và $\mathrm{pH}$ nước bọt.

*Trường Đại học Y Dược Thái Nguyên

Chịu trách nhiệm chính: Lê Thị Thu Hằng

Email: hang.thithule@gmail.com

Ngày nhận bài: 16/3/2021

Ngày phản biện khoa học: 13/4/2021

Ngày duyệt bài: 7/5/2021

\section{Lê Thị Thu Hằng*, Trần Phương Nga*}

Các mẫu nước bọt được lấy ở trạng thái nghi, sau khi nhai xylitol và đo lưu lượng theo quy trình chuẩn, $\mathrm{pH}$ được xác định bằng máy đo $\mathrm{pH}$ Hanna. Kết quả cho thấy, $86 \%$ mẫu nước bọt ở trạng thái nghi có lưu lượng ở mức bình thường, $100 \%$ mấu nước bọt ở trạng thái kích thích có lưu lượng nước bọt bình thường. Hơn nữa, lưu lượng nước bọt ở trạng thái nghi $(0,47 \pm 0,24 \mathrm{ml} /$ phút) thấp hơn rõ so với lưu lượng nước bọt $(2,84 \pm 0,9 \mathrm{ml} /$ phút) sau nhai keo cao su xylitol $(p<0,001)$. PH nước bọt ở trạng thái nghì $(6,85 \pm 0,56)$ thấp hơn rõ so với sau khi nhai kẹo xylitol $(7,09 \pm 0,34)$ với $p=0,011$. Kết luận: Nhai kẹo xylitol có tác dụng làm tăng lưu lượng và pH nước bọt. 